\title{
Review
}

Journal of Innate

Immunity
J Innate Immun 2013;5:348-357

DOI: $10.1159 / 000345943$
Received: October 15, 2012

Accepted after revision: November 20, 2012

Published online: December 21, 2012

\section{Tissue-Specific Neutrophil Recruitment into the Lung, Liver, and Kidney}

\author{
Jan Rossaint Alexander Zarbock \\ Max Planck Institute for Molecular Biomedicine, and Department of Anaesthesiology, Intensive Care and \\ Pain Medicine, University Hospital Münster, Münster, Germany
}

\section{Key Words}

Neutrophil $\cdot$ Recruitment $\cdot$ Leukocyte $\cdot$ Lung $\cdot$ Liver •

Kidney $\cdot$ Inflammation

\begin{abstract}
The recruitment of immune cells is crucial for the development of inflammatory processes. The classical recruitment cascade of neutrophils into inflamed tissues is well understood and consists of capturing, rolling, slow rolling, arrest, postadhesion strengthening, crawling, and transmigration. While this commonly agreed paradigm might be applicable to most peripheral tissues, recruitment mechanisms may substantially vary in different organs such as the lung, liver, and kidney. These organs are highly specialized tissues with unique cell populations and structural organization, which enables them to fulfill their individual functions. The published research over the last decade has shed some light on organ-specific mechanisms of neutrophil recruitment and helped to generate a deeper understanding of the specific recruitment mechanisms involved in this process. The aim of this review is to highlight current concepts of tissue-specific differences and similarities of neutrophil recruitment into the lung, liver, and kidney.

Copyright $\odot 2012$ S. Karger AG, Basel
\end{abstract}

\section{Introduction}

The innate immune system plays a pivotal role as the first line of host defense and as a mediator of inflammatory processes. A key element of the innate immune response is the recruitment of immune cells to sites of inflammation. A tightly controlled neutrophil recruitment is essential for the successful control of pathogens. A defect in mechanisms regulating neutrophil recruitment, as seen in the leukocyte adhesion deficiency syndromes, causes disorders such as recurrent infections [1]. In contrast, an inadequate increase of recruited neutrophils may lead to overshooting inflammation and severe tissue and organ damage [2]. Research over the last decades has established a uniform paradigm of neutrophil recruitment into inflamed tissues. This classical recruitment cascade involves distinct steps in a canonical sequence. The recruitment of neutrophils to sites of inflammation usually takes place in postcapillary venules of the systemic microcirculation. The first step of the cascade is the interaction of neutrophils with endothelial cells (capturing), followed by rolling along the endothelium, transition to selectin-mediated slow rolling, and chemokineinduced arrest [3]. Capturing and rolling are mainly mediated by the interaction of selectins expressed on inflamed endothelial cells with their counterreceptors (e.g. PSGL-1) on neutrophils [4], which may induce an intra-

Prof. Dr. med. Alexander Zarbock

Department of Anesthesiology, Intensive Care and Pain Medicine University of Münster, Albert-Schweitzer-Campus 1, Gebäude A1 DE-48149 Münster (Germany)

E-Mail zarbock@uni-muenster.de 
cellular signaling cascade leading to the activation of $\beta_{2^{-}}$ integrins on neutrophils [5]. Following selectin engagement, the $\beta_{2}$-integrin LFA- 1 is forced into an extended conformation in which the integrin can interact with endothelial adhesion molecules leading to the transition from rolling to slow rolling $[6,7]$. During slow rolling, neutrophils are exposed to different chemokines presented on inflamed endothelial cells which bind to their receptors on neutrophils and mediate $\beta_{2}$-integrin-dependent arrest $[8,9]$. In addition to this pathway, previously published studies demonstrated that E-selectin engagement in the absence of $\mathrm{G}_{\mathrm{i}}$ signaling can also induce neutrophil arrest [10-12]. E-selectin signaling cooperates with chemokine signaling to recruit neutrophils into inflamed tissue. After arresting on the inflamed endothelium, the neutrophils crawl on and subsequently transmigrate through the endothelial cell layer via a trans- or paracellular route in order to emigrate from the vessel [13]. Upon arrival at the inflamed tissue, neutrophils may clear pathogens by phagocytosis or produce reactive oxygen species in order to combat exogenous pathogens and release inflammatory mediators [14]. Recent studies have also shown that intravascular adherent neutrophils may generate neutrophil extracellular traps in the liver and lung microcirculation during systemic inflammatory processes $[15,16]$. These DNA-based structures can catch circulating bacteria and may represent an alternative mechanism of pathogen clearance exerted by neutrophils [17].

Platelets are best known as primary mediators of hemostasis, but these cells are also involved in inflammatory processes. It has been demonstrated that platelets play an active role in both innate and adaptive immunity $[18,19]$. Activated platelets adhering to leukocytes and/or endothelial cells may modulate neutrophil recruitment. The initial interaction of platelets with neutrophils is mediated by the binding of P-selectin on the surface of activated platelets to PSGL-1 on neutrophils [18]. This cell-cell interaction is further stabilized by the subsequent interaction of the activated platelet integrin $\alpha_{\text {IIb }} \beta_{\text {III }}$ to neutrophil $\beta_{2}$-integrins via fibrinogen. This cell-cell interaction promotes the recruitment of neutrophils into inflamed tissue $[18,20]$. In addition, activated platelets secrete several inflammatory cytokines which can directly activate neutrophils and also indirectly modulate leukocyte recruitment by enhancing the expression of different adhesion molecules on endothelial cells [18]. Platelets can attach to endothelial cells by binding of the constitutively expressed glycoprotein (GP)Ib/IX/V complex on platelets to the von Willebrand factor expressed on activated endothelial cells or in the subendothelial space [21]. Binding of this complex to the von Willebrand factor initiates the activation of the integrin $\alpha_{\text {IIb }} \beta_{\text {III }}$ on platelets via 'outside-in' signaling [22], resulting in shape change, spreading, secretion, and aggregation [23]. GPIb $\alpha$ is also a low-affinity ligand for P-selectin [24]. Since its density on the platelet membrane is very high, GPIb $\alpha$ can mediate P-selectin-dependent rolling on activated endothelium and platelet-platelet interactions [25]. Furthermore, GPIb $\alpha$ has been shown to be a ligand for the integrin $\alpha_{M} \beta_{2}$ (Mac-1) on neutrophils and this interaction is physiologically relevant for the recruitment of leukocytes [26]. As activated platelets can bind to neutrophils, platelets adherent to the inflamed vascular endothelium may actively participate in the modulation of inflammation by acting as a bridge between leukocytes and endothelial cells.

The classical leukocyte recruitment cascade was mainly established in the microcirculation of the cremaster muscle by using intravital microscopy [3]. However, recent studies suggest that recruitment mechanisms in the microcirculation of other organs substantially deviate from this paradigm (table 1). This review highlights the available evidence for tissue-specific neutrophil recruitment mechanisms in the lung, liver, and kidneys.

\section{Neutrophil Recruitment into the Lung}

The lung tissue is characterized by its unique anatomical architecture. The smallest functional unit is the airfilled alveolus, which is separated by a thin interstitial tissue membrane from the microvascular bed that spans around the alveolus space and forms a huge system of small capillaries with a vascular diameter between 2 and $15 \mu \mathrm{m}$. The lung is continuously exposed to exogenous pathogens and requires an intact and efficient immune surveillance to control infections [27]. Neutrophil recruitment into the lung occurs mainly in the small capillaries spanning the alveolar network and not in postcapillary venules as observed in the systemic circulation [28, 29]. Due to the small diameter of the lung capillaries, neutrophils have to change their shape to squeeze through the capillary bed [28]. Furthermore, the blood flow velocity in the capillary network of the lung is relatively low [30]. It is thought that the low blood flow velocity together with the shape change of neutrophils accounts for the increased transit time of neutrophils through the lung and for the so-called 'marginated pool of neutrophils' in the pulmonary microvasculature under physiological conditions (fig. 1a) [31]. 
Table 1. Adhesion molecules involved in neutrophil recruitment into different organs

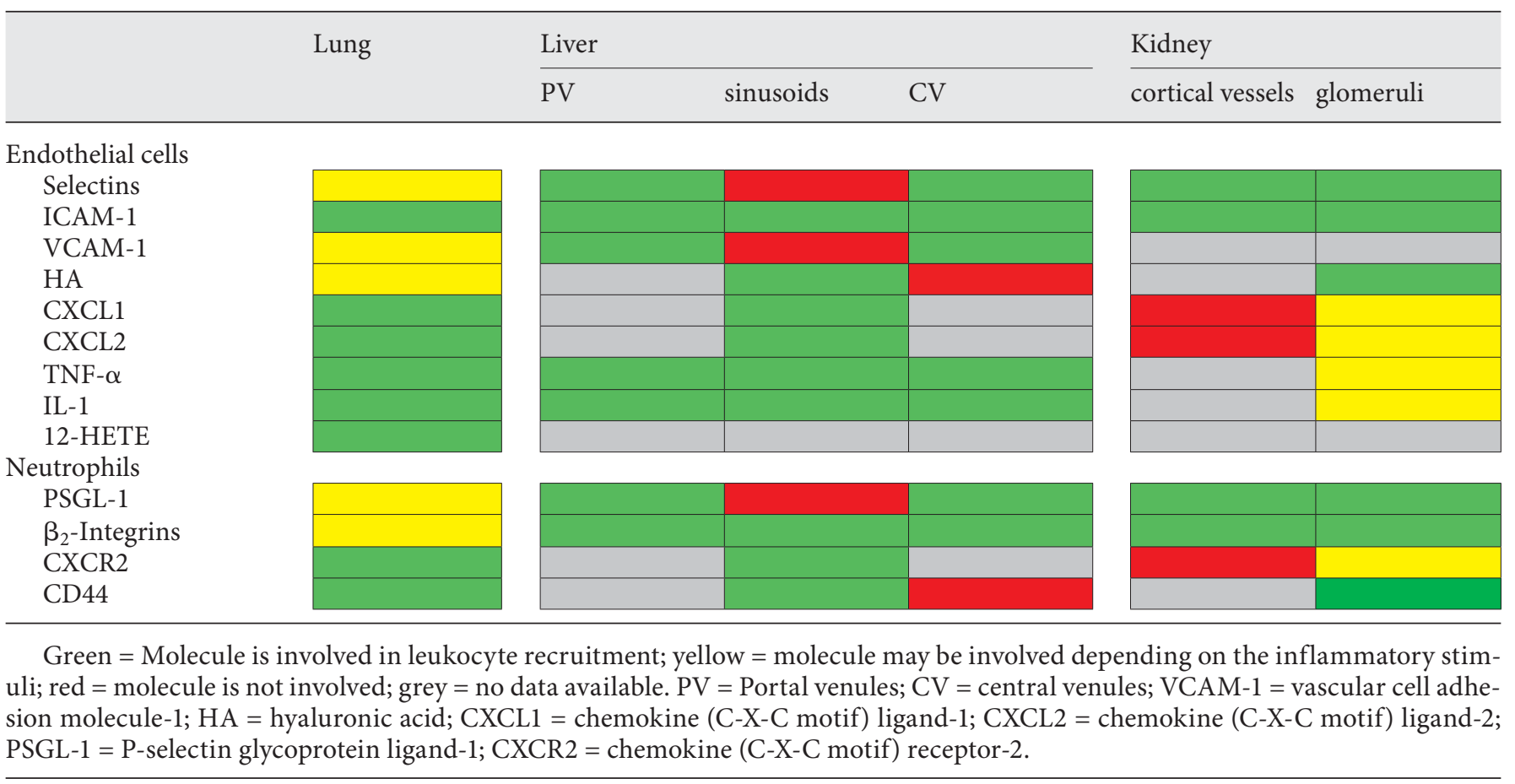

Acute lung injury (ALI) is a severe clinical disorder, which may be caused by direct insults (e.g. pneumonia or aspiration of gastric content) or by indirect insults (e.g. sepsis or transfusion) [32]. The induced inflammation seen during the development of ALI causes neutrophil recruitment into the inflamed tissue, alveolar edema formation, deposition of hyaline membranes, and a compromised gas exchange, which may account for the high morbidity and mortality of this disease [32]. The recruitment of neutrophils is considered as a central element in the pathogenesis of ALI [33]. The number of recruited neutrophils in the alveolar space is increased during ALI. In animal models, it has been shown that neutrophil depletion dampens the development of ALI $[33,34]$. Changes in the deformability of neutrophils caused by actin fiber formation and rearrangement of the cytoskeleton following neutrophil activation have been implicated as one of the first steps of neutrophil recruitment from the marginated pool into the lung tissue during ALI (fig. 1a) [35, 36]. Inhibition of actin fiber formation may decrease neutrophil recruitment during ALI [37]. Thus, the unique anatomical microarchitecture of the lung tissue determines neutrophil recruitment.
Chemokines presented on the inflamed pulmonary endothelial cells are essential for neutrophil recruitment into lung during ALI [38]. Binding of chemokines to their respective receptors on neutrophils induces an intracellular signaling cascade leading to rearrangement of the cytoskeleton and integrin activation, important for leukocyte recruitment [38]. In the lung, resident pulmonary macrophages are able to produce and release chemokines in response to lung injury and are a major source of proinflammatory mediators, e.g. interleukin (IL)-8 (CXCL8), IL-1, tumor necrosis factor- $\alpha$ (TNF- $\alpha$ ), and 12-hydroxyeicosatetraenoic acid (12-HETE) [39, 40].

Under inflammatory conditions, 12/15-lipoxygenase (12/15-LO) is expressed in the lung monocytes/macrophages and is involved in ALI. The product of 12/15-LO, the lipid mediator 12-HETE, is involved in the regulation of the vascular permeability and neutrophil recruitment into the lung after inducing LPS- or acid-induced ALI (fig. 1b) $[40,41]$. It was demonstrated that $12 / 15-\mathrm{LO}$ in hematopoietic cells is necessary for neutrophil recruitment into the interstitial and intra-alveolar compartment of the lung, whereas the accumulation of neutrophils in the lung microvasculature is also regulated by nonhema- 


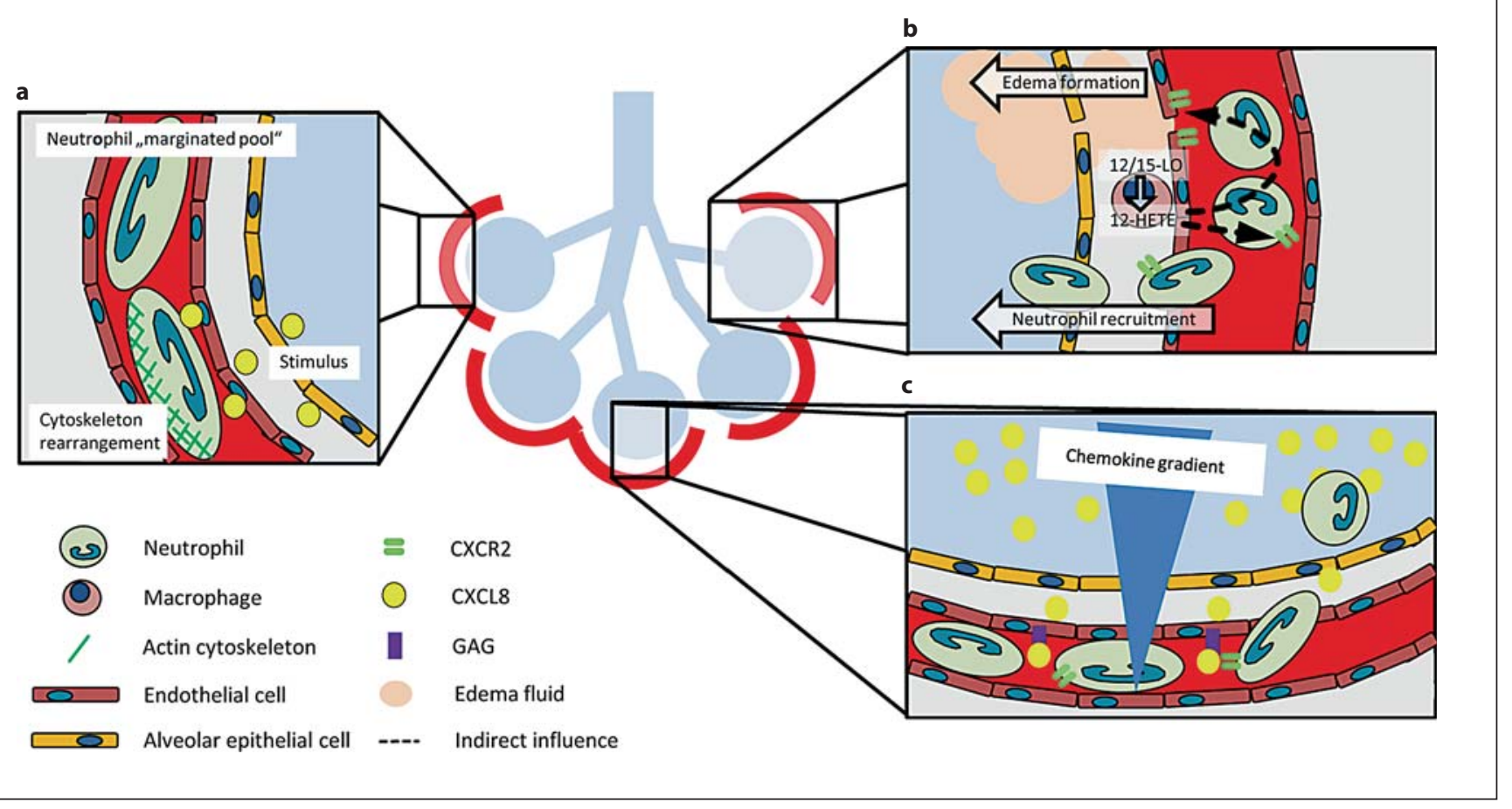

Fig. 1. Neutrophil recruitment into the lung. a Neutrophils have to change their shape to squeeze through the small vessels of the pulmonary microcirculation. The increased transit time results in a marginated neutrophil pool in the lung. Neutrophil stiffening by cytoskeleton rearrangement after stimulation participates in neutrophil recruitment into the lung. b The lipid mediator 12HETE produced by $12 / 15$-LO in lung macrophages modulates chemokine-chemokine receptor balance and increases vascular permeability and neutrophil recruitment in ALI. c A chemokine gradient with the highest chemokine concentration in the alveolar compartment and the presentation of chemokines by glycosaminoglycans facilitate neutrophil recruitment into the alveolar compartment. topoietic $12 / 15$-LO [41]. In addition, the vascular permeability increase upon induction of ALI was abolished in 12/15-LO-deficient mice and in WT mice after pharmacological blockade of 12/15-LO. 12/15-LO-deficient mice also showed improved gas exchange, reduced vascular permeability increase, and prolonged survival in the acid-induced ALI model. Reconstitution experiments revealed that 12-HETE regulates vascular permeability through a CXCR2-dependent mechanism (fig. 1b) [40, 41]. These data suggest that 12/15-LO-derived 12-HETE is a key regulator of chemokine and chemokine receptor balance.

The human chemokine CXCL8 (IL-8) is a ligand for the chemokine receptors CXCR1 and CXCR2. In the murine system, CXCL1 (KC) and CXCL2 (MIP-2) are binding partners for murine CXCR2. The chemokine CXCL8 accumulates in the BAL of patients during ALI $[42,43]$. During the development of the ALI, a chemokine gradient between the alveolar, interstitial, and intravascular space develops with the highest concentration of the chemokine in the alveolar space (fig. 1c) [42, 44]. This chemokine gradient induces neutrophil migration towards the alveolar space. On the endothelial cells, different chemokines bind to and are presented by glycosaminoglycans expressed on endothelial cells (fig. 1c) $[45,46]$. The monomer-dimer equilibrium of CXCL8 is important for the binding of CXCL8 to glycosaminoglycans and affects its ability to recruit neutrophils [47]. In animal models, it has been shown that the CXCR2 receptor on neutrophils is one of the most important chemokine receptors involved in neutrophil recruitment into the lung (fig. 1c) [48-51]. Pharmacological inhibition of the chemokine receptor CXCR2 on neutrophils reduced neutrophil recruitment, vascular permeability, and improved gas exchange following induction of ALI [51]. Furthermore, CXCR2 is also expressed on endothelial cells [52]. The CXCR2 receptor on endothelial cells directly influences neutrophil recruitment and vascular permeability after 
LPS stimulation, demonstrating that the chemokine-chemokine receptor axis is important in the development of ALI (fig. 1c) [52, 53]. The activation of CXCR2 on endothelial cells causes the generation of actin stress fibers, which leads to cell retraction and increased vascular permeability and may also contribute to the recruitment of neutrophils [52].

The role of selectins in neutrophil recruitment during ALI varies in different murine models and depends on the underlying cause of ALI. Depending on the inflammatory stimulus, neutrophil recruitment into the inflamed lung can be selectin dependent or independent. Intratracheal administration of LPS from Escherichia coli causes E-selectin-dependent neutrophil recruitment [20]. Selectins are also necessary for neutrophil recruitment in murine models of ALI following administration of IgG and complement activation [54, 55]. However, neutrophil recruitment following administration of LPS from Streptococcus pneumoniae or Salmonella enteritidis is selectin independent [56]. Similar to selectins, the influence of $\beta_{2}$-integrins on neutrophil recruitment in experimental models of ALI varies and depends on the type of insult. For example, neutrophil recruitment was found to be integrin dependent in ALI models caused by IL-1 and E. coli, whereas neutrophil recruitment was integrin independent following the induction of the ALI by instillation of C5a or during S. pneumoniae [57-60].

Platelets play an important role in neutrophil recruitment into the lung. It has been shown that platelets interact with neutrophils in the blood during the development of acid-induced ALI [61]. P-selectin expressed on platelets is required for this cell-cell interaction, as blocking Pselectin by a monoclonal anti-P-selectin antibody abolishes platelet-neutrophil aggregates and also reduces neutrophil recruitment, vascular permeability, and improves gas exchange during acid-induced ALI [61]. In addition, activated platelets secrete proinflammatory mediators, such as chemokines and lipid mediators including thromboxane $A_{2}[18,61]$. Binding of locally produced thromboxane $\mathrm{A}_{2}$ to thromboxane receptors on endothelial cells causes upregulation of intercellular adhesion molecule-1 (ICAM-1) on the cell surface and may indirectly modulate neutrophil recruitment [62]. It has been shown that platelet depletion improves gas exchange, reduces vascular permeability, and increases survival [61]. Grommes et al. [63] reported that the CCL5-CXCL4 heterodimer released from platelets in LPS-, acid-, and sepsis-induced ALI is involved in neutrophil recruitment and disruption of this heterodimer decreased neutrophil recruitment and improved ALI.

\section{Neutrophil Recruitment into the Liver}

The liver is the central metabolic organ and it fulfills many synthetic and excretory functions, e.g. carbohydrate, lipid and protein metabolism, energy storage by production of glycogen, and excretion of fats, drugs and metabolic waste products via secretion of bile. The liver can be affected by numerous infectious and noninfectious pathologies causing tissue inflammation and injury. However, there is evidence that the recruitment of neutrophils into the liver deviates from the classical leukocyte recruitment cascade [64].

The liver has a unique, dual blood supply. It receives arterial blood from the hepatic artery supplying the organ with oxygenated blood. In addition, the portal vein drains large portions of the splanchnic organs, e.g. the spleen and the intestines, and transports this nutrientrich blood to the liver. The two blood supplies merge at the hepatic sinusoids and are drained via the central, postsinusoidal venules. The liver's sinusoidal endothelium has a unique architecture. The sinusoidal endothelial cells lack a common basal lamina and tight junctions and rather form a mesh with numerous holes with an average diameter of about $0.1 \mu \mathrm{m}$ instead of a tightly sealed cell layer (fig. 2) [65]. In addition, the sinusoidal endothelial cells express low levels of vascular cell adhesion molecule- 1 and they do not express CD31, CD34, and VE-cadherin [66]. In contrast, ICAM-1 is expressed in much higher levels than on endothelial cells in the systemic microcirculation [66, 67]. While neutrophil recruitment in the portal and central venules of the liver shares many similarities with the classical paradigm of neutrophil recruitment in the systemic microcirculation, the recruitment mechanisms are substantially different in sinusoidal vessels $[64,68]$. The unique ultrastructural and molecular features of the endothelial cells in the liver sinusoidal vessels may explain the differences in neutrophil recruitment during liver inflammation [69]. The compartment between the endothelial cells and the hepatocytes is known as the Disse space (fig. 2) [70]. The fenestration of the endothelial cells in combination with the absence of the basal lamina allows an easy exchange of fluids and solutes between the Disse space and the intravascular space. The sinusoids are small vessels and their diameter $(15-30 \mu \mathrm{m})$ is generally just slightly bigger than the diameter of neutrophils [71]. The sinusoidal endothelial cells in the liver do not produce Weibel-Palade bodies and lack E- and P-selectin $[66,67,72]$. Thus, selectin-mediated neutrophil rolling is not observed in the liver sinusoids $[64,68]$. This fact is strengthened by the finding that 


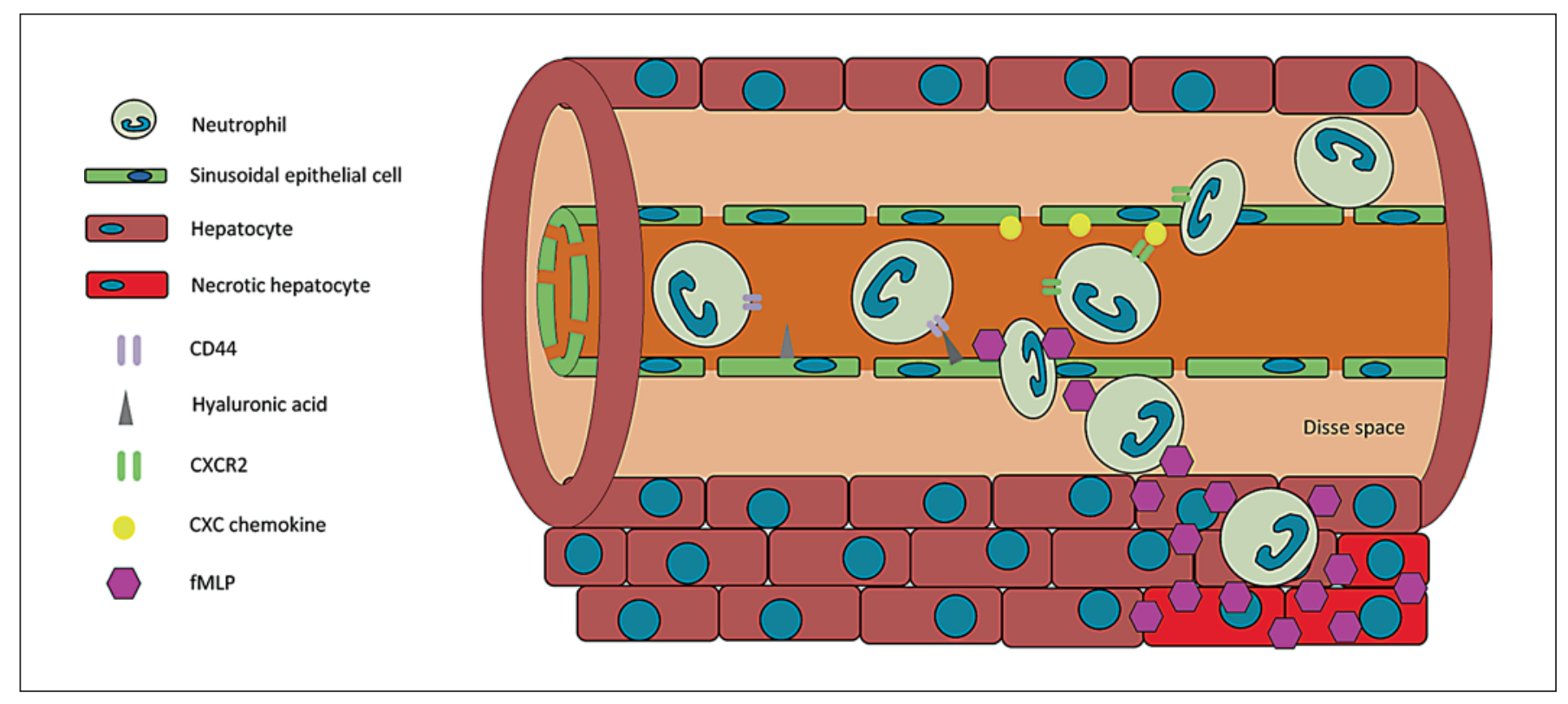

Fig. 2. Neutrophil recruitment into the liver. Neutrophils are recruited in the sinusoids of the liver by chemokines and by binding of CD44 to hyaluronic acid on sinusoidal endothelial cells. The release of inflammatory mediators, such as fMLP, participates in the recruitment of intravascular neutrophils to sites of liver injury.

the recruitment of neutrophils into the liver in response to fMLP administration was not affected in knockout mice lacking E- and P-selectin. In vivo studies investigating neutrophil recruitment in LPS- or TNF- $\alpha$-induced liver injury could also demonstrate the absence of selectin-mediated rolling in liver sinusoids, while neutrophil recruitment in the portal (presinusoidal) venules was selectin dependent $[64,68]$. Recent research has demonstrated that neutrophil recruitment in the liver sinusoids depends on the binding of CD44 on neutrophils to hyaluronic acid on sinusoidal endothelial cells, which is expressed in liver tissue under basal conditions with a distinctive increase in response to inflammatory stimuli (fig. 2) [73]. Another known mechanism of neutrophil recruitment in the liver sinusoids is chemokine-mediated arrest as demonstrated by in vivo studies (fig. 2) [74-76]. Chemokines and cytokines are implicated in neutrophil adhesion to sinusoidal endothelial cells, including TNF$\alpha$ and the CXC chemokines CXCL1 and CXCL2 in mice $[77,78]$. While the chemokine presentation on the sinusoidal endothelial cells mediates the initial intravascular arrest of neutrophils, a recent study demonstrated that fMLP released from necrotic cells triggers neutrophil chemotaxis to inflamed liver tissue (fig. 2) [76].

The participation of platelets in hepatic neutrophil recruitment during systemic endotoxemia by cecal ligation and puncture in rats has been described [79]. Apart from a possible direct interaction with neutrophils, platelets contribute to the generation of an inflammatory microenvironment by modulating chemokine presentation, and platelet depletion significantly reduced the recruitment of neutrophils in an inflammatory model of bile duct ligation-induced cholestasis [80].

\section{Neutrophil Recruitment into the Kidney}

The kidneys are organs that are essential in the urinary system and also serve homeostatic functions such as the regulation of electrolytes, the maintenance of the acid-base balance, and the regulation of blood pressure. In producing urine, the kidneys excrete wastes such as urea and ammonium, and they are also responsible for the reabsorption of water, amino acids, and glucose. The kidneys also produce hormones including erythropoietin, calcitriol, and the enzyme renin. In contrast to other tissues, the kidney has two distinct capillary networks. The first capillary network is located in the glomeruli and participates in the production of plasma ultrafiltrate which enters the nephron. After leaving the glomeruli, the blood enters the second renal capillary network surrounding the nephrons in the renal medulla. This second 
a Cortical postcapillary venules

b Glomerular vessels
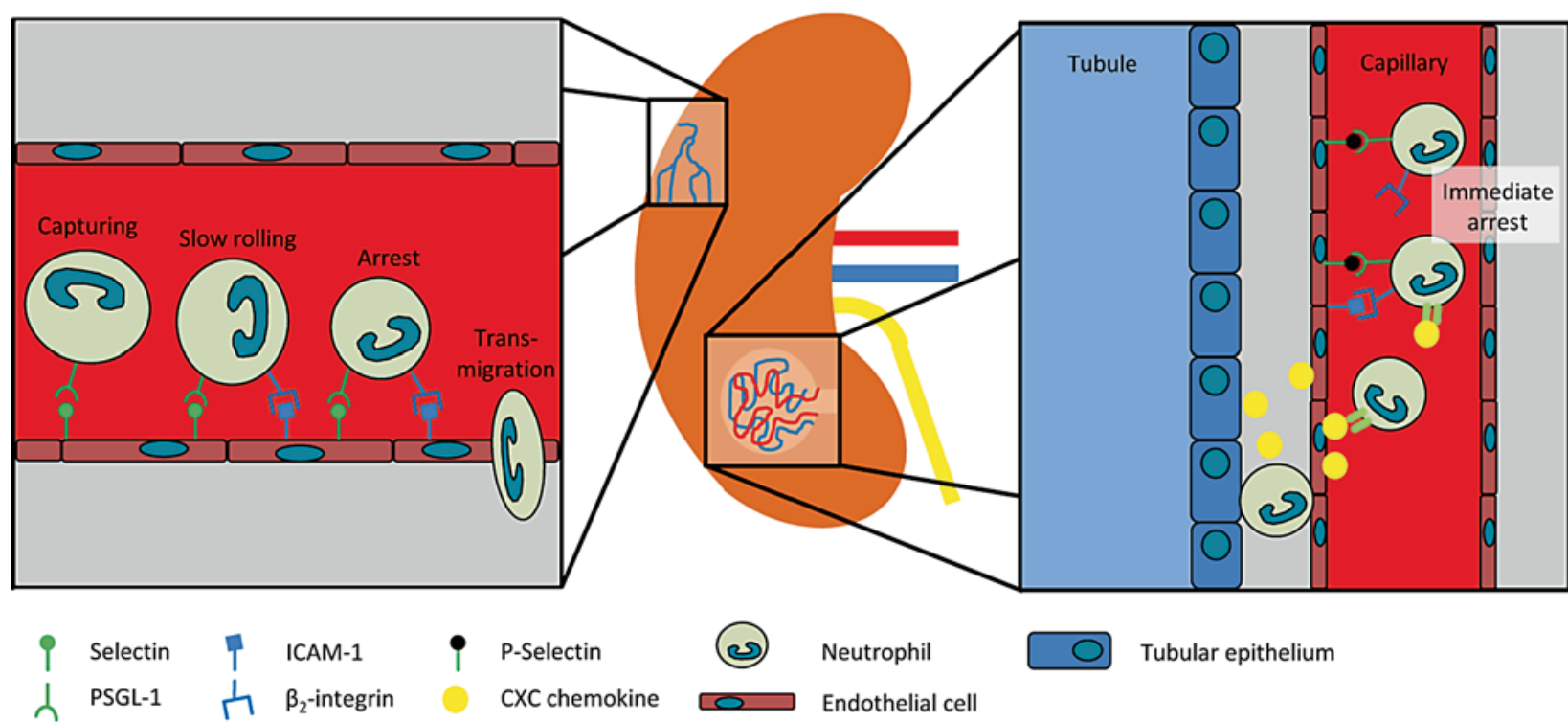

Fig. 3. Neutrophil recruitment into the kidney. a Neutrophil recruitment in the cortical vessels of the kidney is E-selectin dependent and involves selectin-mediated capturing and the transition from rolling to slow rolling by the binding of the $\beta_{2}$-integrin LFA-1 on neutrophils to ICAM-1 on endothelial cells. b Neutrophil recruitment in the glomerular capillaries is mediated by the interaction of P-selectin binding to PSGL-1 on neutrophils and results in chemokine-triggered $\beta_{2}$-integrin-dependent arrest without prior rolling.

capillary network participates in the process of fluid recovery from the ultrafiltrate and urine concentration.

Leukocyte recruitment into the kidney occurs in capillaries of the renal glomeruli and in postcapillary venules of the renal cortex $[81,82]$. The neutrophil dependence of acute kidney injury has been demonstrated in various mouse models, including ischemia-reperfusion injury (IRI) and cisplatin-induced kidney injury [83, 84]. Following IRI, selectins play an important role for neutrophil recruitment [85]. The blockade of E-selectin with a monoclonal antibody protected mice from acute kidney injury after IRI and reduced postischemic neutrophil infiltration into the kidney parenchyma $[82,85]$. Likewise, P-selectin-deficient mice had less neutrophil infiltration and a decreased severity of acute kidney injury after IRI [86]. However, P-selectin is not just expressed by endothelial cells but also by platelets. Studies with bone marrow-chimeric mice revealed that P-selectin on platelets rather than endothelial P-selectin is necessary for neutrophil recruitment into the kidney after IRI [87]. Recently, we demonstrated by intravital mi- croscopy that neutrophil recruitment in the postcapillary venules of the cortex of the kidney depends on Eselectin following IRI. Furthermore, we demonstrated that the two signaling molecules Slp76 (SH2 domaincontaining leukocyte phosphoprotein of $76 \mathrm{kDa}$ ) and ADAP (adhesion- and degranulation-promoting adaptor protein) in neutrophils are both implicated in selectin-mediated integrin activation and neutrophil recruitment into the injured kidney (fig. 3a) [82]. In addition, the binding of endothelial CD44 to hyaluronic acid on neutrophils contributes to neutrophil recruitment into the kidney after IRI [88]. CD44 is weakly expressed under physiological conditions, but CD44 expression on endothelial cells sharply increases after induction of IRI [88]. Awad et al. [89] described the spatiotemporal organization of neutrophil recruitment into the kidney after IRI as a process of intravascular neutrophil margination and transendothelial migration with a negative regulatory role of the adenosine $2 \mathrm{~A}$ receptor on neutrophil recruitment. Due to technical difficulties in the visualization of leukocyte recruitment into the injured kidneys, 
it is noteworthy to mention that most of the published in vivo data were acquired in a mouse model of hydronephrotic kidneys, which were subsequently rendered to inflammatory stimuli [90]. Using this model, it could be demonstrated that leukocyte recruitment in the inflamed glomerular capillaries following administration of an antibody against the glomerular basement membrane occurs via immediate arrest requiring endothelial P-selectin and ICAM-1 and leukocyte PSGL-1 and $\beta_{2^{-}}$ integrins, but does not involve rolling (fig. 3b) [91]. In addition to selectins, cytokines and chemokines play an important role in neutrophil recruitment into the kidney [92].

Similar to the lung, platelets are also involved in the recruitment of immune cells into the kidney. Recent intravital microscopy studies could show that platelets accumulate in glomerular capillaries after inducing inflammation by administration of an antibody directed against the glomerular basement membrane. Platelet recruitment occurred via an $\alpha_{\mathrm{IIb}} \beta_{\mathrm{III}} / \mathrm{GPVI}$-dependent pathway [93]. Interestingly, leukocyte recruitment was platelet dependent and the depletion of neutrophils also led to a reduced number of accumulated platelets, indicating a cooperative mechanism of heterotypic interaction between platelets and neutrophils $[91,93]$.

\section{Conclusions}

The mechanisms of neutrophil recruitment have been investigated over the past decades. Although the generally accepted steps of the neutrophil recruitment cascade are well defined and the underlying molecular mechanisms of this process have been unveiled to a certain extent, it has to be kept in mind that these results were mostly obtained in the cremaster muscle and the systemic microcirculation. Although these general principles might be valid for a lot of tissues, it has become evident that the recruitment of neutrophils into different organs may deviate from this general idea. In addition, the recruitment mechanisms in the same organ may vary with different inflammatory stimuli. The understanding of the precise, tissue-specific molecular mechanisms involved in the recruitment of neutrophils from the circulation has evolved over the past decade. An improved knowledge of the tissue specificity of neutrophil recruitment might aid in the development of future tissue-specific therapeutic approaches in the treatment of inflammatory diseases.

\section{Acknowledgements}

J.R. is supported by the Interdisciplinary Center for Clinical Research (IZKF) of the University Münster (SEED 01/12 to J.R.). A.Z. is supported by the Deutsche Forschungsgemeinschaft (ZA428/3-1, ZA428/6-1, ZA428/8-1, and SFB1009 to A.Z.).

\section{References}

1 Hanna S, Etzioni A: Leukocyte adhesion deficiencies. Ann NY Acad Sci 2012;1250:5055.

-2 Pinheiro da Silva F, Soriano FG: Neutrophils recruitment during sepsis: critical points and crossroads. Front Biosci 2009; 14:44644476.

-3 Ley K, Laudanna C, Cybulsky MI, Nourshargh S: Getting to the site of inflammation: the leukocyte adhesion cascade updated. Nat Rev Immunol 2007;7:678-689.

4 Zarbock A, Ley K, McEver RP, Hidalgo A: Leukocyte ligands for endothelial selectins: specialized glycoconjugates that mediate rolling and signaling under flow. Blood 2011; 118:6743-6751.

5 Zarbock A, Lowell CA, Ley K: Spleen tyrosine kinase Syk is necessary for E-selectininduced alpha(L)beta(2) integrin-mediated rolling on intercellular adhesion molecule-1. Immunity 2007;26:773-783.
6 Kuwano Y, Spelten O, Zhang H, Ley K, Zarbock A: Rolling on E- or P-selectin induces the extended but not high-affinity conformation of LFA-1 in neutrophils. Blood 2010; 116:617-624

7 Yago T, Shao B, Miner JJ, Yao L, Klopocki AG, Maeda K, Coggeshall KM, McEver RP: E-selectin engages PSGL-1 and CD44 through a common signaling pathway to induce integrin alphaLbeta2-mediated slow leukocyte rolling. Blood 2010;116:485-494.

-8 Ley K: Arrest chemokines. Microcirculation 2003;10:289-295.

-9 Colditz IG, Schneider MA, Pruenster M, Rot A: Chemokines at large: in-vivo mechanisms of their transport, presentation and clearance. Thromb Haemost 2007;97:688-693.

10 Smith ML, Olson TS, Ley K: CXCR2- and Eselectin-induced neutrophil arrest during inflammation in vivo. J Exp Med 2004;200: 935-939.
11 Kunkel EJ, Ley K: Distinct phenotype of E-selectin-deficient mice. E-selectin is required for slow leukocyte rolling in vivo. Circ Res 1996;79:1196-1204.

-12 Mueller H, Stadtmann A, Van Aken H, Hirsch E, Wang D, Ley K, Zarbock A: Tyrosine kinase Btk regulates E-selectin-mediated integrin activation and neutrophil recruitment by controlling phospholipase $\mathrm{C}$ (PLC) gamma2 and PI3Kgamma pathways. Blood 2010;115:3118-3127.

13 Woodfin A, Voisin MB, Nourshargh S: Recent developments and complexities in neutrophil transmigration. Curr Opin Hematol 2010;17:9-17.

14 Lacy P, Eitzen G: Control of granule exocytosis in neutrophils. Front Biosci 2008; 13: 5559-5570.

15 McDonald B, Urrutia R, Yipp BG, Jenne CN, Kubes P: Intravascular neutrophil extracellular traps capture bacteria from the bloodstream during sepsis. Cell Host Microbe 2012;12:324-333. 
-16 Caudrillier A, Kessenbrock K, Gilliss BM, Nguyen JX, Marques MB, Monestier M, Toy P, Werb Z, Looney MR: Platelets induce neutrophil extracellular traps in transfusion-related acute lung injury. J Clin Invest 2012; 122:2661-2671.

${ }_{17}$ Yipp BG, Petri B, Salina D, Jenne CN, Scott BN, Zbytnuik LD, Pittman K, Asaduzzaman $\mathrm{M}, \mathrm{Wu} \mathrm{K}$, Meijndert HC, Malawista SE, de Boisfleury Chevance A, Zhang K, Conly J, Kubes P: Infection-induced NETosis is a dynamic process involving neutrophil multitasking in vivo. Nat Med 2012;18:1386-1393.

-18 Zarbock A, Polanowska-Grabowska RK, Ley K: Platelet-neutrophil-interactions: linking hemostasis and inflammation. Blood Rev 2007;21:99-111.

19 Smyth SS, McEver RP, Weyrich AS, Morrell CN, Hoffman MR, Arepally GM, French PA, Dauerman HL, Becker RC: Platelet functions beyond hemostasis. J Thromb Haemost 2009;7:1759-1766.

-20 Kornerup KN, Salmon GP, Pitchford SC, Liu WL, Page CP: Circulating platelet-neutrophil complexes are important for subsequent neutrophil activation and migration. J Appl Physiol 2010;109:758-767.

-21 Cruz MA, Diacovo TG, Emsley J, Liddington R, Handin RI: Mapping the glycoprotein Ibbinding site in the von Willebrand factor A1 domain. J Biol Chem 2000;275:19098-19105.

-22 Zaffran Y, Meyer SC, Negrescu E, Reddy KB, Fox JE: Signaling across the platelet adhesion receptor glycoprotein Ib-IX induces alpha IIbbeta 3 activation both in platelets and a transfected Chinese hamster ovary cell system. J Biol Chem 2000;275:16779-16787.

-23 Ruggeri ZM: Mechanisms initiating platelet thrombus formation. Thromb Haemost 1997;78:611-616.

-24 Romo GM, Dong JF, Schade AJ, Gardiner EE, Kansas GS, Li CQ, McIntire LV, Berndt MC, Lopez JA: The glycoprotein Ib-IX-V complex is a platelet counterreceptor for P-selectin. J Exp Med 1999;190:803-814.

-25 Andrews RK, Berndt MC: Platelet physiology and thrombosis. Thromb Res 2004;114: 447-453.

-26 Wang Y, Sakuma M, Chen Z, Ustinov V, Shi C, Croce K, Zago AC, Lopez J, Andre P, Plow E, Simon DI: Leukocyte engagement of platelet glycoprotein Ibalpha via the integrin Mac-1 is critical for the biological response to vascular injury. Circulation 2005;112: 2993-3000.

-27 Martin TR, Frevert CW: Innate immunity in the lungs. Proc Am Thorac Soc 2005;2:403411.

-28 Doerschuk CM: Leukocyte trafficking in alveoli and airway passages. Respir Res 2000; 1:136-140.

29 Grommes J, Soehnlein O: Contribution of neutrophils to acute lung injury. Mol Med 2011;17:293-307.
Kuebler WM, Goetz AE: The marginated pool. Eur Surg Res 2002;34:92-100.

31 Wiggs BR, English D, Quinlan WM, Doyle NA, Hogg JC, Doerschuk CM: Contributions of capillary pathway size and neutrophil deformability to neutrophil transit through rabbit lungs. J Appl Physiol 1994;77:463-470.

32 Matthay MA, Ware LB, Zimmerman GA: The acute respiratory distress syndrome. J Clin Invest 2012;122:2731-2740.

33 Abraham E: Neutrophils and acute lung injury. Crit Care Med 2003;31:S195-S199.

34 Abraham E, Carmody A, Shenkar R, Arcaroli J: Neutrophils as early immunologic effectors in hemorrhage- or endotoxemia-induced acute lung injury. Am J Physiol Lung Cell Mol Physiol 2000;279:L1137-L1145.

35 Tanaka H, Nishino M, Dahms TE: Physiologic responses to small emboli and hemodynamic effects of changes in deformability of polymorphonuclear leukocytes in isolated rabbit lung. Microvasc Res 2002;63:81-90.

36 Drost EM, MacNee W: Potential role of IL-8, platelet-activating factor and TNF-alpha in the sequestration of neutrophils in the lung: effects on neutrophil deformability, adhesion receptor expression, and chemotaxis. Eur J Immunol 2002;32:393-403.

37 Worthen GS, Schwab B 3rd, Elson EL, Downey GP: Mechanics of stimulated neutrophils: cell stiffening induces retention in capillaries. Science 1989;245:183-186.

38 Bhatia M, Zemans RL, Jeyaseelan S: Role of chemokines in the pathogenesis of acute lung injury. Am J Respir Cell Mol Biol 2012; 46:566-572.

-39 Wang J, Nikrad MP, Travanty EA, Zhou B, Phang T, Gao B, Alford T, Ito Y, Nahreini P, Hartshorn K, Wentworth D, Dinarello CA, Mason RJ: Innate immune response of human alveolar macrophages during influenza A infection. PLoS One 2012;7:e29879.

40 Zarbock A, Distasi MR, Smith E, Sanders JM, Kronke G, Harry BL, von Vietinghoff S, Buscher K, Nadler JL, Ley K: Improved survival and reduced vascular permeability by eliminating or blocking 12/15-lipoxygenase in mouse models of acute lung injury (ALI). J Immunol 2009;183:4715-4722.

41 Rossaint J, Nadler JL, Ley K, Zarbock A: Eliminating or blocking 12/15-lipoxygenase reduces neutrophil recruitment in mouse models of acute lung injury. Crit Care 2012; 16:R166.

42 Miller EJ, Cohen AB, Matthay MA: Increased interleukin- 8 concentrations in the pulmonary edema fluid of patients with acute respiratory distress syndrome from sepsis. Crit Care Med 1996;24:1448-1454.

43 Kurdowska A, Noble JM, Grant IS, Robertson CR, Haslett C, Donnelly SC: Anti-interleukin-8 autoantibodies in patients at risk for acute respiratory distress syndrome. Crit Care Med 2002;30:2335-2337.
44 Quinton LJ, Nelson S, Zhang P, Boe DM, Happel KI, Pan W, Bagby GJ: Selective transport of cytokine-induced neutrophil chemoattractant from the lung to the blood facilitates pulmonary neutrophil recruitment. Am J Physiol Lung Cell Mol Physiol 2004; 286:L465-L472.

45 Schmidt EP, Yang Y, Janssen WJ, Gandjeva A, Perez MJ, Barthel L, Zemans RL, Bowman JC, Koyanagi DE, Yunt ZX, Smith LP, Cheng SS, Overdier KH, Thompson KR, Geraci MW, Douglas IS, Pearse DB, Tuder RM: The pulmonary endothelial glycocalyx regulates neutrophil adhesion and lung injury during experimental sepsis. Nat Med 2012, E-pub ahead of time.

46 Handel TM, Johnson Z, Crown SE, Lau EK, Proudfoot AE: Regulation of protein function by glycosaminoglycans - as exemplified by chemokines. Annu Rev Biochem 2005;74: 385-410.

-47 Das ST, Rajagopalan L, Guerrero-Plata A, Sai J, Richmond A, Garofalo RP, Rajarathnam $\mathrm{K}$ : Monomeric and dimeric CXCL8 are both essential for in vivo neutrophil recruitment. PLoS One 2010;5:e11754.

$\checkmark 48$ Belperio JA, Keane MP, Lynch JP 3rd, Strieter RM: The role of cytokines during the pathogenesis of ventilator-associated and ventilator-induced lung injury. Semin Respir Crit Care Med 2006;27:350-364.

-49 Strieter RM, Keane MP, Burdick MD, Sakkour A, Murray LA, Belperio JA: The role of CXCR2/CXCR2 ligands in acute lung injury. Curr Drug Targets Inflamm Allergy 2005;4:299-303.

50 Stadtmann A, Zarbock A: CXCR2: from bench to bedside. Front Immunol 2012;3: 263.

51 Zarbock A, Allegretti M, Ley K: Therapeutic inhibition of CXCR2 by Reparixin attenuates acute lung injury in mice. Br J Pharmacol 2008;155:357-364.

52 Reutershan J, Morris MA, Burcin TL, Smith DF, Chang D, Saprito MS, Ley K: Critical role of endothelial CXCR2 in LPS-induced neutrophil migration into the lung. J Clin Invest 2006;116:695-702.

53 Konrad FM, Reutershan J: CXCR2 in acute lung injury. Mediators Inflamm 2012;2012: 740987.

54 Mulligan MS, Miyasaka M, Ward PA: Protective effects of combined adhesion molecule blockade in models of acute lung injury. Proc Assoc Am Phys 1996;108:198-208.

55 Mulligan MS, Warner RL, Rittershaus CW, Thomas LJ, Ryan US, Foreman KE, Crouch LD, Till GO, Ward PA: Endothelial targeting and enhanced antiinflammatory effects of complement inhibitors possessing sialyl Lewisx moieties. J Immunol 1999; 162:49524959. 
56 Mizgerd JP, Meek BB, Kutkoski GJ, Bullard DC, Beaudet AL, Doerschuk CM: Selectins and neutrophil traffic: margination and Streptococcus pneumoniae-induced emigration in murine lungs. J Exp Med 1996;184: 639-645.

-57 Ganter MT, Roux J, Miyazawa B, Howard M, Frank JA, Su G, Sheppard D, Violette SM, Weinreb PH, Horan GS, Matthay MA, Pittet JF: Interleukin-1beta causes acute lung injury via alphavbeta5 and alphavbeta6 integrindependent mechanisms. Circ Res 2008;102: 804-812.

-58 Xu J, Gao XP, Ramchandran R, Zhao YY, Vogel SM, Malik AB: Nonmuscle myosin lightchain kinase mediates neutrophil transmigration in sepsis-induced lung inflammation by activating beta 2 integrins. Nat Immunol 2008;9:880-886.

59 Mizgerd JP, Kubo H, Kutkoski GJ, Bhagwan SD, Scharffetter-Kochanek K, Beaudet AL, Doerschuk CM: Neutrophil emigration in the skin, lungs, and peritoneum: different requirements for CD11/CD18 revealed by CD18-deficient mice. J Exp Med 1997;186: 1357-1364.

60 Hellewell PG, Young SK, Henson PM, Worthen GS: Disparate role of the beta 2-integrin CD18 in the local accumulation of neutrophils in pulmonary and cutaneous inflammation in the rabbit. Am J Respir Cell Mol Biol 1994;10:391-398.

-61 Zarbock A, Singbartl K, Ley K: Complete reversal of acid-induced acute lung injury by blocking of platelet-neutrophil aggregation. J Clin Invest 2006;116:3211-3219.

62 Huang JS, Ramamurthy SK, Lin X, Le Breton GC: Cell signalling through thromboxane A2 receptors. Cell Signal 2004;16:521-533.

63 Grommes J, Alard JE, Drechsler M, Wantha S, Morgelin M, Kuebler WM, Jacobs M, von Hundelshausen P, Markart P, Wygrecka M, Preissner KT, Hackeng TM, Koenen RR, Weber C, Soehnlein O: Disruption of plateletderived chemokine heteromers prevents neutrophil extravasation in acute lung injury. Am J Respir Crit Care Med 2012;185:628636.

-64 Wong J, Johnston B, Lee SS, Bullard DC, Smith CW, Beaudet AL, Kubes P: A minimal role for selectins in the recruitment of leukocytes into the inflamed liver microvasculature. J Clin Invest 1997;99:2782-2790.

- 65 Lalor PF, Shields P, Grant A, Adams DH: Recruitment of lymphocytes to the human liver. Immunol Cell Biol 2002;80:52-64.

-66 Scoazec JY, Feldmann G: The cell adhesion molecules of hepatic sinusoidal endothelial cells. J Hepatol 1994;20:296-300.
67 Steinhoff G, Behrend M, Schrader B, Duijvestijn $A M$, Wonigeit $K$ : Expression patterns of leukocyte adhesion ligand molecules on human liver endothelia. Lack of ELAM-1 and CD62 inducibility on sinusoidal endothelia and distinct distribution of VCAM-1, ICAM-1, ICAM-2, and LFA-3. Am J Pathol 1993;142:481-488.

68 Fox-Robichaud A, Kubes P: Molecular mechanisms of tumor necrosis factor alphastimulated leukocyte recruitment into the murine hepatic circulation. Hepatology 2000;31:1123-1127.

69 McDonald B, Kubes P: Neutrophils and intravascular immunity in the liver during infection and sterile inflammation. Toxicol Pathol 2012;40:157-165.

70 DeLeve LD: Hepatic microvasculature in liver injury. Semin Liver Dis 2007;27:390-400.

71 Wisse E, De Zanger RB, Charels K, Van Der Smissen P, McCuskey RS: The liver sieve: considerations concerning the structure and function of endothelial fenestrae, the sinusoidal wall and the space of Disse. Hepatology 1985;5:683-692.

-72 Scoazec JY, Racine L, Couvelard A, Flejou JF, Feldmann G: Endothelial cell heterogeneity in the normal human liver acinus: in situ immunohistochemical demonstration. Liver 1994;14:113-123.

73 McDonald B, McAvoy EF, Lam F, Gill V, de la Motte C, Savani RC, Kubes P: Interaction of CD44 and hyaluronan is the dominant mechanism for neutrophil sequestration in inflamed liver sinusoids. J Exp Med 2008; 205:915-927.

74 Li X, Klintman D, Liu Q, Sato T, Jeppsson B, Thorlacius H: Critical role of CXC chemokines in endotoxemic liver injury in mice. J Leukocyte Biol 2004;75:443-452.

75 Patrick AL, Rullo J, Beaudin S, Liaw P, FoxRobichaud AE: Hepatic leukocyte recruitment in response to time-limited expression of TNF-alpha and IL-1beta. Am J Physiol Gastrointest Liver Physiol 2007;293:G663G672.

76 McDonald B, Pittman K, Menezes GB, Hirota SA, Slaba I, Waterhouse CC, Beck PL, Muruve DA, Kubes P: Intravascular danger signals guide neutrophils to sites of sterile inflammation. Science 2010;330:362-366.

-77 Schlayer HJ, Laaff H, Peters T, Woort-Menker M, Estler HC, Karck U, Schaefer HE, Decker K: Involvement of tumor necrosis factor in endotoxin-triggered neutrophil adherence to sinusoidal endothelial cells of mouse liver and its modulation in acute phase. J Hepatol 1988;7:239-249.

78 Bajt ML, Farhood A, Jaeschke H: Effects of CXC chemokines on neutrophil activation and sequestration in hepatic vasculature. Am J Physiol Gastrointest Liver Physiol 2001; 281:G1188-G1195.

-79 Croner RS, Hoerer E, Kulu Y, Hackert T, Gebhard MM, Herfarth C, Klar E: Hepatic platelet and leukocyte adherence during endotoxemia. Crit Care 2006;10:R15.
80 Laschke MW, Dold S, Menger MD, Jeppsson B, Thorlacius H: Platelet-dependent accumulation of leukocytes in sinusoids mediates hepatocellular damage in bile duct ligationinduced cholestasis. Br J Pharmacol 2008; 153:148-156.

81 Li L, Huang L, Sung SS, Vergis AL, Rosin DL, Rose CE Jr, Lobo PI, Okusa MD: The chemokine receptors CCR2 and CX3CR1 mediate monocyte/macrophage trafficking in kidney ischemia-reperfusion injury. Kidney Int 2008;74:1526-1537.

82 Block H, Herter JM, Rossaint J, Stadtmann A, Kliche S, Lowell CA, Zarbock A: Crucial role of SLP-76 and ADAP for neutrophil recruitment in mouse kidney ischemia-reperfusion injury. J Exp Med 2012;209:407-421.

83 Kelly KJ, Williams WW Jr, Colvin RB, Meehan SM, Springer TA, Gutierrez-Ramos JC, Bonventre JV: Intercellular adhesion molecule-1-deficient mice are protected against ischemic renal injury. J Clin Invest 1996;97: 1056-1063.

84 Tadagavadi RK, Reeves WB: Renal dendritic cells ameliorate nephrotoxic acute kidney injury. J Am Soc Nephrol 2010;21:53-63.

85 Singbartl K, Ley K: Protection from ischemia-reperfusion induced severe acute renal failure by blocking E-selectin. Crit Care Med 2000;28:2507-2514.

- 86 Singbartl K, Green SA, Ley K: Blocking Pselectin protects from ischemia/reperfusioninduced acute renal failure. FASEB J 2000;14: 48-54.

87 Singbartl K, Forlow SB, Ley K: Platelet, but not endothelial, $\mathrm{P}$-selectin is critical for neutrophil-mediated acute postischemic renal failure. FASEB J 2001;15:2337-2344.

-88 Rouschop KM, Roelofs JJ, Claessen N, da Costa Martins P, Zwaginga JJ, Pals ST, Weening JJ, Florquin S: Protection against renal ischemia reperfusion injury by $\mathrm{CD} 44$ disruption. J Am Soc Nephrol 2005;16:20342043.

89 Awad AS, Rouse M, Huang L, Vergis AL, Reutershan J, Cathro HP, Linden J, Okusa MD: Compartmentalization of neutrophils in the kidney and lung following acute ischemic kidney injury. Kidney Int 2009;75: 689-698.

90 Kitching AR, Kuligowski MP, Hickey MJ: In vivo imaging of leukocyte recruitment to glomeruli in mice using intravital microscopy. Methods Mol Biol 2009;466:109-117.

91 Kuligowski MP, Kitching AR, Hickey MJ: Leukocyte recruitment to the inflamed glomerulus: a critical role for platelet-derived P-selectin in the absence of rolling. J Immunol 2006;176:6991-6999.

92 Chung AC, Lan HY: Chemokines in renal injury. J Am Soc Nephrol 2011;22:802-809.

-93 Devi S, Kuligowski MP, Kwan RY, Westein E, Jackson SP, Kitching AR, Hickey MJ: Platelet recruitment to the inflamed glomerulus occurs via an alphaIIbbeta3/GPVI-dependent pathway. Am J Pathol 2010;177:1131-1142. 